\title{
Phosphorus Balance in Rats with Hypophosphatemia Induced by Lanthanum Carbonate
}

\author{
Munehiro Yoshida ${ }^{1,2^{*}}$, Ryota Hosomi ${ }^{1,3}$, Mai Kunimatsu ${ }^{1}$, Mikiko Nakamura ${ }^{1}$, Kenji Fukunaga ${ }^{1,2}$, \\ Seiji Kanda ${ }^{4}$, Toshimasa Nishiyama ${ }^{4}$ \\ ${ }^{1}$ Laboratory of Food and Nutritional Sciences, Faculty of Chemistry, Materials and Bioengineering, Kansai University, Suita, Japan; \\ ${ }^{2}$ Organization for Research and Development of Innovative Science and Technology, Kansai University, Suita, Japan; ${ }^{3}$ Division of \\ Food Science and Nutrition, Tottori College, Kurayoshi, Japan; ${ }^{4}$ Department of Public Health, Kansai Medical University, Moriguchi, \\ Japan. \\ Email: *hanmyou4@kansai-u.ac.jp
}

Received November $19^{\text {th }}, 2011$; revised January $10^{\text {th }}, 2012$; accepted January $17^{\text {th }}, 2012$

\begin{abstract}
To examine whether lanthanum carbonate can induce a low phosphorus status in experimental animals, we examined phosphorus balance in rats administered lanthanum carbonate. Male 8-week-old Wistar rats were fed a basal casein-based semi-purified diet or the basal diet supplemented with $0.45 \%$ or $0.90 \%$ lanthanum as lanthanum carbonate for 4 weeks. Lanthanum administration did not influence body or several organ weights and liver function. In rats administered lanthanum, a very small quantity of lanthanum was detected in several organs although the apparent absorption was almost zero. The highest lanthanum concentration was observed in the liver followed by the femur and kidney. Lanthanum was not clearly detected in the brain. Differences in organ lanthanum between $0.45 \%$ and $0.90 \%$ administration groups were not significant; lanthanum accumulation in the body is very low and may reach a plateau in a certain range of intake. Serum phosphorus was decreased and fecal phosphorus was increased by lanthanum administration dose-dependently. Urinary phosphorus excretion was significantly decreased by lanthanum. Since urinary phosphorus of rats fed $0.45 \%$ lanthanum diet decreased to near zero, the highest phosphorus balance was observed in rats fed $0.45 \%$ lanthanum diet. This high balance is considered to be adaptation to the low phosphorus status induced by lanthanum carbonate. These results indicate that lanthanum carbonate can induce hypophosphatemia without any direct side effects and be used to examine the effect of removing phosphorus from the diet in animal nutritional studies.
\end{abstract}

Keywords: Phosphorus; Lanthanum; Balance Test; Semi-Purified Diet; Hypophosphatemia

\section{Introduction}

Phosphorus is a major essential mineral in human and animal nutrition. Inadequate phosphorus intake is expressed as hypophosphatemia and induces anorexia, anemia, muscle weakness, bone pain, rickets and osteomalacia, general debility, increased susceptibility to infection, paresthesias, ataxia, confusion, and even death [1]. To prepare an animal model with a low phosphorus status, several kinds of commercial low phosphorus diet are used [2,3]; however, the detailed composition of these commercial low phosphorus diets is unclear as information on the ingredients of the diet except for phosphorus is not available. Accordingly, it has not been evaluated whether nutrients other than phosphorus are associated with phenomena observed in the experimental low phosphorus status. In an experimental nutrition study using rats, to estimate the intake of each nutrient pre-

${ }^{*}$ Corresponding author. cisely, a semi-purified diet such as the AIN93G or AIN93M diet is used as the standard diet [4]. When a low phosphorus diet is prepared based on the AIN93 diets, potassium should be supplemented because potassium phosphate is removed from the mineral mixture; it is not possible to avoid changing mineral composition other than phosphorus. In addition, a major source of phosphorus in the AIN93 diets is casein-bound phosphate; about $30 \%$ to $50 \%$ of phosphorus is derived from casein; therefore, a severely low phosphorus diet cannot be prepared based on the AIN93 diets.

Lanthanum, a rare-earth metal, has been used industrially as a raw material of ceramic capacitors, optical lenses and semiconductors. On the other hand, trivalent lanthanum ion has high affinity to phosphate ion and has been used as a chemical reagent to suppress the interference of phosphate in the determination of calcium in atomic absorption spectrometry [5]. Recently, attention has focused on the high affinity between lanthanum and 
phosphate, and the use of lanthanum carbonate as a phosphate-binder to decrease the absorption of dietary phosphate in patients with chronic renal failure receiving hemodialysis [6]. This indicates that oral administration of lanthanum carbonate can induce a low-phosphorus status in normal animals who have ingested the AIN93 diets; however, because lanthanum carbonate was developed as a phosphate-binder for human patients with renal failure, the purpose of animal studies using lanthanum carbonate is not to induce hypophosphatemia in normal animals but to prevent hyperphosphatemia and its complications in animals with experimental renal failure [7,8].

Although serious adverse side effects have not been observed in any human cases of long-term lanthanum administration [9], some researchers have pointed out the adverse effects of lanthanum and the harmfulness of long-term lanthanum administration mainly based on animal experiments; lanthanum decreased liver function $[10,11]$. Generally, adverse effects induced by chemical substances may occur more readily in animals fed semipurified diets than those fed commercial conventional diets composed of natural products containing several phytochemicals. Accordingly, it is necessary to examine the effect of lanthanum carbonate administration on liver function in rats fed semi-purified diets when lanthanum carbonate is used as an inducer of a low phosphorus status.

In the present study, to examine whether lanthanum carbonate can be used to induce a low phosphorus status in experimental animals fed a casein-based semi-purified diet, we measured urinary and fecal phosphorus excretion and phosphorus balance in normal rats fed an AIN93M diet supplemented with lanthanum carbonate and discussed the interaction between lanthanum and phosphorus in the gut. In addition, we examined the effect of lanthanum carbonate administration on liver function in these rats.

\section{Materials and Methods}

\subsection{Reagents}

Lanthanum carbonate $\left(\mathrm{La}_{2}\left(\mathrm{CO}_{3}\right)_{3} \cdot \mathrm{xH}_{2} \mathrm{O}\right)$ was purchased from Nacalai Tesque, Inc. (Kyoto, Japan). Lanthanum content in this reagent was $50 \%$. The ingredients of animal diets were purchased from Oriental Yeast Co. (Tokyo, Japan). Lanthanum and rhodium standard solution, as well as metal-free grade $\mathrm{HNO}_{3}$ and $\mathrm{HClO}_{4}$ were purchased from Wako Pure Chemical Industries (Osaka, Japan).

\subsection{Animal Experiments}

The experimental protocol was reviewed and approved by the Animal Ethics Committee of Kansai Medical
University and followed the "Guide for the Care and Use of Experimental Animals" of the Prime Minister's Office of Japan. Experimental animals were housed in plastic cages in a room under a controlled $12 \mathrm{~h}$ light (8:00 to 20:00) and dark cycle at a temperature of $23^{\circ} \mathrm{C}$ to $24^{\circ} \mathrm{C}$ and humidity of $60 \%$. The animals were given experimental diets and deionized water ad libitum during the entire experimental period.

Eighteen male 8-week-old Wistar rats (Shimizu Lab. Supplies Co. Ltd., Kyoto, Japan) were divided into three groups. The mean and SD of the initial body weights of the eighteen rats were 316 and $12 \mathrm{~g}$, respectively. One group was fed a casein-based semi-purified basal diet (AIN93M diet [4]) and the other two groups were fed the basal diet supplemented with $0.45 \%$ or $0.90 \%(0.032$ or $0.065 \mathrm{mmol} / \mathrm{g}$, respectively) of lanthanum as lanthanum carbonate for 4 weeks. Analysis showed that the basal AIN93M diet contained phosphorus at a level of 3.24 $\mathrm{mg} / \mathrm{g}(0.105 \mathrm{mmol} / \mathrm{g})$. Lanthanum could not be detected in the basal diet. In the third week of feeding, the rats were transferred to metabolic cages and urine and feces samples were collected for 3 days. After the end of the feeding periods, the rats were anesthetized with sodium pentobarbital, blood was collected from the abdominal aorta, and the liver, kidney, brain, spleen, small intestine and femur were excised, washed with saline, blotted and weighed

A part of each blood sample was transferred to a heparinized tube and subjected to hemoglobin determination. Serum was separated from the remainder of the blood and subjected to serum biochemical tests (total protein, triglyceride, total cholesterol, alanine aminotransferase, aspartate aminotransferase, urea nitrogen, creatinine, iron, total iron-binding capacity, calcium, magnesium and phosphorus). The hemoglobin measurement and serum biochemical tests were performed by a commercial service system (Japan Medical Laboratory, Osaka, Japan).

\subsection{Analysis of Lanthanum and Phosphorus}

Up to $2 \mathrm{~g}$ of the organ samples was heated with $10 \mathrm{~mL}$ metal-free $\mathrm{HNO}_{3}$ until the disappearance of insoluble components, and then $2 \mathrm{~mL}$ metal-free $\mathrm{HClO}_{4}$ was added to the digestion mixture. The digestion mixture was further heated until the appearance of the white vapor of $\mathrm{HClO}_{4}$. The volume of the digest was made up to $10 \mathrm{~mL}$ with pure water. Approximately $1 \mathrm{~g}$ basal diet or feces was digested with metal-free $\mathrm{HNO}_{3}$ and $\mathrm{HClO}_{4}$ similarly to the digestion of organs. Urine was diluted with pure water.

Lanthanum in the digests and the diluted urine was determined by inductively coupled plasma mass spectrometry (ICPMS) with direct nebulization. The ICPMS 
operating conditions were as follows: instrument, ICPM8500 (Shimadzu, Kyoto, Japan); forward power, $1200 \mathrm{~W}$; coolant gas flow rate, $7.0 \mathrm{~L} / \mathrm{min}$; auxiliary gas flow rate, $1.5 \mathrm{~L} / \mathrm{min}$; nebulizer gas flow rate, $0.58 \mathrm{~L} / \mathrm{min}$; sampling depth, $5.0 \mathrm{~mm}$; integration time, $2.0 \mathrm{~s}$; number of run, 20; mode of analysis, pulse; isotopes monitored, ${ }^{139} \mathrm{La}$. A rhodium isotope $\left({ }^{103} \mathrm{Rh}\right)$ was used as an internal standard. In the organ samples, the detection limit was $4 \mathrm{ng} / \mathrm{g}$ wet tissue.

Phosphorus in the digested samples and the diluted urine was determined by colorimetric method using vanadomolybdate [12].

\subsection{Statistics}

Experimental data were assessed by one-way analysis of variance. When the $F$ value was significant $(p<0.05)$, the Tukey-Kramer multiple range test was performed to determine which pairs of the means were significantly different $(p<0.05)$. When the analytical values were below the detection limit, a half-value of the detection limit was used. These statistical tests were performed using a personal computer (eMac; Apple Computer, Cupertino, CA) with the operating system Mac OS 9.2 and statistical program package StatView-J version 5.0 (Abacus Concept, Berkeley, CA).

\section{Results}

Table 1 shows whole body and several organ weights of rats fed experimental diets with or without lanthanum carbonate for 4 weeks. No influence of lanthanum administration was observed.

Lanthanum concentrations in several organs are summarized in Table 2. Lanthanum was not detected in the organs of rats fed the basal diet without lanthanum. In rats administered lanthanum, the highest lanthanum concentration was observed in the liver followed by the femur and kidney. For the brain, lanthanum was detected in

Table 1. Effect of dietary lanthanum on body and organ weights of rats.

\begin{tabular}{cccc}
\hline & \multicolumn{3}{c}{ Dietary lanthanum added } \\
\cline { 2 - 4 } & None & $0.45 \%$ & $0.90 \%$ \\
\hline Feed intake (g/d) & $18.6 \pm 0.5$ & $18.4 \pm 0.4$ & $19.1 \pm 0.4$ \\
Whole body (g) & $397 \pm 5$ & $391 \pm 8$ & $381 \pm 8$ \\
$\begin{array}{c}\text { Liver } \\
\text { (g/100g body weight) }\end{array}$ & $3.11 \pm 0.10$ & $3.03 \pm 0.09$ & $3.09 \pm 0.05$ \\
$\begin{array}{c}\text { Kidney } \\
\text { (g/100g body weight) }\end{array}$ & $0.56 \pm 0.01$ & $0.55 \pm 0.02$ & $0.57 \pm 0.01$ \\
$\begin{array}{c}\text { Brain } \\
\text { (g/100g body weight) }\end{array}$ & $0.45 \pm 0.02$ & $0.45 \pm 0.03$ & $0.49 \pm 0.01$ \\
\hline
\end{tabular}

Rats were fed AIN93M diet with or without lanthanum carbonate for 4 weeks. Values are the means \pm SEM $(n=6)$.
Table 2. Lanthanum contents in several organs of rats fed experimental diets with or without lanthanum carbonate for 4 weeks.

\begin{tabular}{cccc}
\hline & \multicolumn{3}{c}{ Dietary lanthanum added } \\
\cline { 2 - 4 } & None & $0.45 \%$ & $0.90 \%$ \\
\hline Liver (ng/g) & $<4^{\mathrm{a}}$ & $1103 \pm 141^{\mathrm{b}}$ & $1522 \pm 209^{\mathrm{b}}$ \\
Kidney (ng/g) & $<4^{\mathrm{a}}$ & $279 \pm 38^{\mathrm{b}}$ & $320 \pm 40^{\mathrm{b}}$ \\
Brain (ng/g) & $<4^{\mathrm{a}}$ & $<4^{\mathrm{a}}$ & $8 \pm 3^{\mathrm{a}}$ \\
Spleen (ng/g) & $<4^{\mathrm{a}}$ & $48 \pm 14^{\mathrm{ab}}$ & $70 \pm 27^{\mathrm{b}}$ \\
Small intestine (ng/g) & $<4^{\mathrm{a}}$ & $32 \pm 8^{\mathrm{b}}$ & $31 \pm 5^{\mathrm{b}}$ \\
Femur (ng/g) & $<4^{\mathrm{a}}$ & $592 \pm 95^{\mathrm{b}}$ & $674 \pm 82^{\mathrm{b}}$ \\
\hline
\end{tabular}

Rats were fed AIN93M diet with or without lanthanum carbonate for 4 weeks. Values are the means \pm SEM $(n=6)$. Means in the same row not sharing a common superscript letter differ significantly $(\mathrm{p}<0.05)$.

two of six rats fed the $0.90 \%$ lanthanum diet but the difference in the lanthanum concentration between the rats fed $0.90 \%$ lanthanum diet and other diets was not significant. An increase in the dietary lanthanum level showed a tendency for the concentration of organ lanthanum to increase but the difference between the $0.45 \%$ and the $0.90 \%$ lanthanum administration groups was not significant.

Table 3 shows the effects of lanthanum administration on hemoglobin and serum biochemical tests of the rats. Serum phosphorus was significantly decreased by lanthanum administration and the decrease was dependent on the dose of lanthanum administered; serum phosphorus was decreased $20 \%$ or $36 \%$ by dietary lanthanum at $0.45 \%$ or $0.90 \%$, respectively. On the other hand, serum calcium was significantly increased in rats fed the $0.90 \%$ lanthanum diet. Other serum biochemical tests and hemoglobin were not influenced by lanthanum administration.

Table 4 shows the phosphorus balance of rats in the third week of feeding experimental diets with or without lanthanum carbonate. To clarify the interaction between the two elements, the unit is mmol in this table. Fecal phosphorus excretion was significantly increased by lanthanum administration, which dose-dependently lowered the apparent absorption of phosphorus, which was decreased $17 \%$ or $42 \%$ by dietary lanthanum at $0.45 \%$ or $0.90 \%$, respectively. On the other hand, urinary phosphorus excretion was significantly decreased by lanthanum. Since urinary phosphorus of rats fed the $0.45 \%$ lanthanum diet decreased to near zero, the difference between $0.45 \%$ and $0.90 \%$ lanthanum administration groups was not significant. As a result, the highest phosphorus balance was observed in rats fed the $0.45 \%$ lanthanum diet.

The lanthanum balance was also described in Table 4. 
Table 3. Effect of dietary lanthanum on hemoglobin and serum biochemical tests.

\begin{tabular}{|c|c|c|c|}
\hline \multirow{2}{*}{ Tests } & \multicolumn{3}{|c|}{ Dietary lanthanum added } \\
\hline & None & $0.45 \%$ & $0.90 \%$ \\
\hline Hemoglobin (g/dL) & $14.9 \pm 0.1$ & $14.9 \pm 0.1$ & $14.8 \pm 0.1$ \\
\hline Total protein (mg/dL) & $5.6 \pm 0.1$ & $5.6 \pm 0.1$ & $5.6 \pm 0.1$ \\
\hline Triglyceride (mg/dL) & $28 \pm 4$ & $24 \pm 3$ & $27 \pm 4$ \\
\hline $\begin{array}{l}\text { Total cholesterol } \\
\text { (mg/dL) }\end{array}$ & $84 \pm 4$ & $70 \pm 6$ & $76 \pm 3$ \\
\hline $\begin{array}{l}\text { Alanine aminotransferase } \\
\qquad(\mathrm{U} / \mathrm{mL})\end{array}$ & $48 \pm 3$ & $44 \pm 3$ & $53 \pm 4$ \\
\hline $\begin{array}{l}\text { Aspartate aminotransferase } \\
\qquad(\mathrm{U} / \mathrm{mL})\end{array}$ & $80 \pm 2$ & $83 \pm 3$ & $89 \pm 7$ \\
\hline $\begin{array}{l}\text { Urea nitrogen } \\
\text { (mg/dL) }\end{array}$ & $21 \pm 1$ & $21 \pm 2$ & $22 \pm 1$ \\
\hline Creatinine (mg/dL) & $0.32 \pm 0.02$ & $0.30 \pm 0.01$ & $0.28 \pm 0.03$ \\
\hline Iron $(\mu \mathrm{g} / \mathrm{dL})$ & $152 \pm 12$ & $149 \pm 16$ & $148 \pm 16$ \\
\hline $\begin{array}{l}\text { Total iron-binding } \\
\text { capacity }(\mu \mathrm{g} / \mathrm{dL})\end{array}$ & $552 \pm 47$ & $546 \pm 39$ & $537 \pm 40$ \\
\hline Calcium (mg/dL) & $10.2 \pm 0.1^{\mathrm{a}}$ & $10.1 \pm 0.1^{\mathrm{a}}$ & $10.7 \pm 0.1^{\mathrm{b}}$ \\
\hline Magnesium (mg/dL) & $2.0 \pm 0.2$ & $2.2 \pm 0.3$ & $2.1 \pm 0.3$ \\
\hline Phosphorus (mg/dL) & $4.95 \pm 0.15^{\mathrm{c}}$ & $3.97 \pm 0.15^{\mathrm{b}}$ & $3.17 \pm 0.18^{\mathrm{a}}$ \\
\hline
\end{tabular}

Rats were fed AIN93M diet with or without lanthanum carbonate for 4 weeks. Values are the means \pm SEM $(n=6)$. Means not sharing a common superscript letter differ significantly $(p<0.05)$ in calcium and phosphorus.

Since lanthanum could not be detected in the basal diet, lanthanum in feces and urine of rats fed the basal diet was not analyzed. In rats administered lanthanum, fecal lanthanum excretion was almost equal to the lanthanum intake; apparent absorption of lanthanum was almost zero. On the other hand, urinary lanthanum excretion was very low compared to the dietary intake; urinary excretion did not contribute to the balance. Increase of dietary lanthanum intake did not affect urinary lanthanum excretion.

\section{Discussion}

In its clinical use as a phosphate-binder, the maximum dose of lanthanum is 2000 to $3000 \mathrm{mg} / \mathrm{d}$ [13]. The total daily amount of diet for a human adult is about $500 \mathrm{~g}$ on a dry weight basis. Thus, when roughly estimated, the dietary lanthanum level of $0.45 \%$ or $0.90 \%$ corresponds to a dose of 2250 or $4500 \mathrm{mg} / \mathrm{d}$ to humans, respectively; a dietary level of $0.45 \%$ almost equals the maximum dose to humans.

When dietary lanthanum $(0.45 \%$ or $0.90 \%)$ was compared by molar concentration with dietary phosphorus (3.24 mg/g), the present dosage $(0.032$ or $0.065 \mathrm{mmol} / \mathrm{g}$ ) was lower than that of dietary phosphorus $(0.105 \mathrm{mmol} / \mathrm{g})$.
Table 4. Phosphorus balance and fecal and urinary excretion of lanthanum after 3 week feeding.

\begin{tabular}{|c|c|c|c|}
\hline & \multicolumn{3}{|c|}{ Dietary lanthanum added } \\
\hline & None & $0.45 \%$ & $0.90 \%$ \\
\hline \multicolumn{4}{|l|}{ Phosphorus } \\
\hline Intake (mmol/d) & $1.98 \pm 0.08^{\mathrm{a}}$ & $1.88 \pm 0.17^{\mathrm{a}}$ & $1.78 \pm 0.18^{\mathrm{a}}$ \\
\hline $\begin{array}{l}\text { Fecal excretion } \\
(\mathrm{mmol} / \mathrm{d})\end{array}$ & $0.30 \pm 0.02^{\mathrm{a}}$ & $0.49 \pm 0.03^{b}$ & $0.80 \pm 0.03^{c}$ \\
\hline $\begin{array}{c}\text { Apparent } \\
\text { absorption (mmol/d) }\end{array}$ & $1.68 \pm 0.14^{\mathrm{c}}$ & $1.39 \pm 0.07^{b}$ & $0.98 \pm 0.07^{\mathrm{a}}$ \\
\hline $\begin{array}{c}\text { Apparent } \\
\text { absorption rate (\%) }\end{array}$ & $84.2 \pm 0.7^{c}$ & $72.5 \pm 3.6^{\mathrm{b}}$ & $53.2 \pm 3.9^{\mathrm{a}}$ \\
\hline $\begin{array}{l}\text { Urinary excretion } \\
\text { (mmol/d) }\end{array}$ & $0.95 \pm 0.11^{\mathrm{b}}$ & $0.11 \pm 0.01^{\mathrm{a}}$ & $0.04 \pm 0.02^{\mathrm{a}}$ \\
\hline Balance (mmol/d) & $0.72 \pm 0.14^{\mathrm{a}}$ & $1.29 \pm 0.16^{\mathrm{b}}$ & $0.94 \pm 0.15^{\mathrm{ab}}$ \\
\hline \multicolumn{4}{|l|}{ Lanthanum } \\
\hline Intake (mmol/d) & - & $0.58 \pm 0.05^{\mathrm{a}}$ & $1.10 \pm 0.11^{\mathrm{b}}$ \\
\hline $\begin{array}{l}\text { Fecal excretion } \\
(\mathrm{mmol} / \mathrm{d})\end{array}$ & - & $0.59 \pm 0.09^{\mathrm{a}}$ & $1.08 \pm 0.16^{\mathrm{b}}$ \\
\hline $\begin{array}{l}\text { Apparent absorption } \\
(\mathrm{mmol} / \mathrm{d})\end{array}$ & - & $-0.01 \pm 0.08^{\mathrm{a}}$ & $0.02 \pm 0.09^{\mathrm{a}}$ \\
\hline $\begin{array}{l}\text { Urinary excretion } \\
\text { (nmol/d) }\end{array}$ & - & $68.2 \pm 8.9^{\mathrm{a}}$ & $69.2 \pm 19.8^{\mathrm{a}}$ \\
\hline Balance (mmol/d) & - & $-0.01 \pm 0.08^{\mathrm{a}}$ & $0.02 \pm 0.09^{\mathrm{a}}$ \\
\hline
\end{tabular}

After 3-week feeding with experimental diets with or without lanthanum carbonate, urine and feces samples were collected for 3 days. Since lanthanum could not be detected in basal diet, lanthanum in feces and urine samples of rats fed the basal diet was not analyzed. Values are the means \pm SEM $(n=6)$. Means in the same row not sharing a common superscript letter differ significantly $(p<0.05)$.

As shown in Table 4, lanthanum added to the experimental diets clearly increased fecal phosphorus excretion and decreased the apparent absorption of phosphorus. As a result, serum phosphorus was also decreased by lanthanum administration; however, the increase of fecal phosphorus excretion did not reach that expected from the molar ratio of phosphorus and lanthanum in the diets. This indicates that some lanthanum taken from the diet is not bound to phosphorus in the gut even if the intake of lanthanum is less than that of phosphorus. On the other hand, dietary restriction of phosphate is a well-known stimulator of small intestinal apical sodium-phosphate co-transport [14]. Accordingly, the intestinal absorption of phosphorus may have been accelerated in response to the decrease of serum phosphorus concentration in rats administered lanthanum.

In rats administered lanthanum, urinary phosphorus excretion was markedly decreased. This indicates that urinary phosphorus excretion was suppressed in response to the low phosphorus status. As a result, a higher phosphorus balance was observed in rats fed the $0.45 \%$ lan- 
thanum diet. This high balance is considered to be adaptation to the low phosphorus status induced by lanthanum carbonate. If this state continues, it is expected that the low phosphorus status will improve and hypophosphatemia will not be manifested. In fact, Slatopolsky et al. observed that the low serum phosphorus concentration in rats administered lanthanum recovered to a similar level in control rats 110 days after the start of lanthanum administration [15]. It can therefore be said that the decrease in serum phosphorus due to the administration of lanthanum is temporary in normal animals without hyperphosphatemia.

It has been observed that the decrease in body and liver weights and the lowered liver function were caused by lanthanum administration in rats with experimental chronic renal failure [10,11]; however, in the present study using normal rats, these adverse effects were not observed. This indicates that there is a difference in the effect of lanthanum administration between normal rats and rats with experimental renal failure; toxicity of lanthanum is very low, at least in normal rats.

Fecal lanthanum excretion was almost equal to lanthanum intake; the apparent absorption and balance of this element were almost zero. However, lanthanum was accumulated in the tissues; a very small quantity of lanthanum was absorbed although the apparent absorption was almost zero. Among the tissues examined, the highest lanthanum deposition was observed in the liver followed by the femur and kidney. Such a deposition pattern is the same as in previous reports [11,15]. Higher accumulation in the liver than in the kidney might reflect not urine but bile as the main excretion route of this element. In fact, urinary lanthanum excretion was extremely low and almost constant regardless of the dietary lanthanum intake. Difference in the dietary lanthanum level did not significantly affect tissue lanthanum concentrations. In addition, the present accumulation levels are close to those of rats fed a $1.5 \%$ lanthanum diet for 110 days [15]. This indicates that lanthanum accumulation in the body may reach a plateau in a certain range of intake, and the tissue lanthanum concentration stabilizes almost regardless of the dosage or the period of administration in normal animals without biliary obstruction or renal failure. Since it has been reported that the administration of lanthanum influenced the neurobehavioral development of the rats [16], it is important to examine the deposition of this element in the brain; however, as shown in Table 2, accumulation of lanthanum in the brain was not observed.

Phosphate-binders other than lanthanum carbonate are also used clinically; anion exchange resin and calcium carbonate; however, these phosphate-binders are not adequate to induce hypophosphatemia in experimental animals because anion exchange resin is not a specific binder to phosphate, and calcium carbonate may affect the absorption of other minerals and trace elements. On the other hand, since binding of lanthanum to phosphate is specific, it is thought that lanthanum does not directly affect the absorption of other mineral and trace elements. In fact, hemoglobin and serum iron were not changed by lanthanum administration, while excess calcium inhibited iron absorption and induced a low iron status [17]. As shown in Table 3, serum calcium was significantly increased in rats fed the $0.90 \%$ lanthanum diet. Calcium absorption may have increased because binding of phosphate to lanthanum increased soluble calcium in the gut; lanthanum did not influence calcium absorption directly but phosphate binding to lanthanum influenced calcium absorption.

The present results indicate that lanthanum carbonate can induce hypophosphatemia without any side effects and can be used to examine the effect of removing phosphorus from the diet in animal nutritional studies.

\section{REFERENCES}

[1] Food and Nutrition Board Institute of Medicine, "Phosphorus," In: Dietary Reference Intakes for Calcium, Phosphorus, Magnesium, Vitamin D, and Fluoride, National Academy Press, Washington DC, 1997, pp. 146189.

[2] A. Jara, E. Lee, D. Stauber, F. Moatamed, A. J. Felsenfeld and C. R. Kleeman, "Phosphate Depletion in the Rat: Effect of Bisphosphates and the Calcemic Response to PTH,” Kidney International, Vol. 55, No. 4, 1999, pp. 1434-1443. doi:10.1046/j.1523-1755.1999.00395.x

[3] T. Yoshida, N. Yoshida, T. Monkawa, M. Hayashi and T. Saruta, "Dietary Phosphorus Deprivation Induces 25Hydroxyvitamin $\mathrm{D}_{3} 1 \alpha$-Hydroxylase Gene Expression,” Endocrinology, Vol. 142, No. 5, 2001, pp. 1720-1726. doi:10.1210/en.142.5.1720

[4] P. G. Reeves, F. H. Nielsen and G. C. Fahey, "AIN-93 Purified Diets for Laboratory Rodents: Final Report of the American Institute of Nutrition Ad Hoc Writing Committee on the Reformulation of the AIN-76A Rodent Diet,” Journal of Nutrition, Vol. 123, No. 11, 1993, pp. 1939-1951.

[5] M. W. Welch, D. W. Hamar and M. J. Fettman, "Method Comparison to Calcium Determination by Flame Atomic Absorption Spectrophotometry in the Presence of Phosphate," Clinical Chemistry, Vol. 36, No. 2, 1990, pp. 351-354.

[6] T. Swainston-Harrison and L. J. Scott, "Lanthanum Carbonate,” Drugs, Vol. 64, No. 9, 2004, pp. 985-996.

[7] I. Z. Ben-Dev, O. Pappo, M. Sklair-Levy, H. Galitzer, Y. Ilan, T. Naveh-Many and J. Silver, "Lanthanum Carbonate Decreases PTH Gene Expression with No Hepatotoxicity in Uraemic Rats," Nephrology Dialysis Transplantation, Vol. 22, No. 2, 2007, pp. 362-368. doi:10.1093/ndt/gfl623

[8] E. Neven, G. Dams, A. Postnov, B. Chen, N. De Clerck, 
M. E. De Broe, P. C. D’Haese and V. Persy, “Adequate Phosphate Binding with Lanthanum Carbonate Attenuates Arterial Calcification in Chronic Renal Failure Rats,” Nephrology Dialysis Transplantation, Vol. 24, No. 6, 2009, pp. 1790-1799. doi:10.1093/ndt/gfn737

[9] A. J. Hutchison, M. E. Barnett, R. J. Krause and G. A. Siami, "Lanthanum Carbonate Treatment, for Up to 6 Years, Is Not Associated with Adverse Effects on the Liver in Patients with Chronic Kidney Disease Stage 5 Receiving Hemodialysis," Clinical Nephrology, Vol. 71, No. 3, 2009, pp. 286-295.

[10] B. Lacour, I. G. Nikolov, N. Joki and T. B. Drüeke, "Lanthanum Carbonate, Body Lanthanum Accumulation and Potential Liver Toxicity," Nephrology Dialysis Transplantation, Vol. 22, No. 6, 2007, pp. 1788-1789. doi:10.1093/ndt/gfm033

[11] I. G. Nikolov, N. Joki, S. Vicca, N. Patey, D. Auchère, J. Benchitrit, J. P. Flinois, M. Ziol, P. Beaune, T. B. Drüeke and B. Lacour, "Tissue Accumulation of Lanthanum as Compared to Aluminum in Rats with Chronic Renal Failure-Possible Harmful Effects after Long-Term Exposure," Nephron Experimental Nephrology, Vol. 115, No. 4, 2010, pp. e112-e121. doi:10.1159/000313492

[12] K. P. Quinlan and M. A. DeSesa, "Spectrophotometric Determination of Phosphorus as Molybdovanadophosphoric Acid," Analytical Chemistry, Vol. 27, No. 10,
1955, pp. 1626-1629. doi:10.1021/ac60106a039

[13] T. Shigematsu and Lanthanum Carbonate Research Group, "Lanthanum Carbonate Effectively Controls Serum Phosphate without Affecting Serum Calcium Levels in Patients Undergoing Hemodialysis,” Therapeutic Apheresis and Dialysis, Vol. 12, No. 1, 2008, pp. 55-61. doi:10.1111/j.1744-9987.2007.00541.X

[14] O. Hattenhauer, M. Traebert, H. Murer and J. Biber, "Regulation of Small Intestinal Na-Pi Type IIb Cotransporter by Dietary Phosphate Intake,” American Journal of Physiology Gastrointestinal and Liver Physiology, Vol. 277, No. 4, 1999, pp. G756-G762.

[15] E. Slatopolsky, H. Liapis and J. Finch, "Progressive Accumulation of Lanthanum in the Liver of Normal and Uremic Rats,” Kidney International, Vol. 68, No. 6, 2005, pp. 2809-2813. doi:10.1111/j.1523-1755.2005.00753.X

[16] L. Feng, H. Xiao, X. He, Z. Li, F. Li, N. Liu, Z. Chai, Y. Zhao and Z. Zhang, "Long-Term Effects of Lanthanum Intake on the Neurobehavioral Development of the Rat," Neurotoxicology and Teratology, Vol. 28, No. 1, 2006, pp. 119-124. doi:10.1016/j.ntt.2005.10.007

[17] L. Hallberg, L. Rossander-Hulten, M. Brune and A. Gleerup, "Calcium and Iron Absorption: Mechanism of Action and Nutritional Importance," European Journal of Clinical Nutrition, Vol. 46, No. 5, 1992, pp. 317-327. 